\title{
Rutas y Espacios Conectados: Las Tierras Altas y Bajas del Oeste Tinogasteño de Catamarca (Ca. 200-1.200 d.C.)
}

\author{
Routes and Connected Spaces: Highlands and Lowlands of West \\ Tinogasta, Catamarca (Ca. 200-1.200 A.D.) \\ Norma Ratto ${ }^{\mathrm{I}}$, Mara Basile ${ }^{\mathrm{II}}$ y Anabel Feely ${ }^{\mathrm{III}}$
}

\begin{abstract}
Resumen
El valle alto mesotérmico (1.900 m.s.n.m.) del bolsón de Fiambalá, las tierras altas de la puna transicional (3.400-4.000 m.s.n.m.) y la alta cordillera andina de Chaschuil (5.000-6.730 m.s.n.m.) estuvieron integrados a través de rutas prehispánicas que facilitaron el acceso a la complementariedad ecológica y constituyeron el soporte para promover, mantener y reforzar las relaciones socioeconómicas, politicas e ideológicas que caracterizaron el desarrollo cultural regional desde el Arcaico Tardio hasta la ocupación incaica. En este trabajo nos concentramos en uno de estos recorridos transitado por las primeras sociedades agropastoriles, denominadas genéricamente formativas o pre-tardias, que ocuparon esta región entre los 200 y 1200 años de la era, aproximadamente. Para ello analizamos aspectos tecnológicos y visuales de la materialidad cerámica recuperada en los sitios emplazados dentro de los diferentes ambientes contrastantes conectados por la ruta. Luego relacionamos los resultados con las características arquitectónicas de los sitios de procedencia del conjunto cerámico para discutir finalmente la existencia de una tradición que se reproduce en el tiempo construyendo un espacio a través de la memoria.
\end{abstract}

Palabras clave: Rutas conectoras, Sociedades Pre-tardias, Cerámica, Arquitectura, NorOeste Argentino.

\section{Abstract}

The high mesothermal valley (1.900 m.a.s.l) of the bolson de Fiambala, the highlands of the transitional puna (3.400-4.000 m.a.s.l) and the high Andean range of Chaschuil (5.000-6.730 m.a.s.l) were integrated by pre-Hispanic routes which facilitated access to ecological complementarity and were key factor to

Museo Etnográfico Juan B. Ambrosetti, Universidad de Buenos Aires, Moreno 350 (1091) Ciudad Autónoma de Buenos Aires, Argentina. Correo-e: nratto@filo.uba.ar

ii CONICET y Museo Etnográfico J. B. Ambrosetti, Universidad de Buenos Aires, Moreno 350 (1091), Ciudad Autónoma de Buenos Aires, Argentina. Correo-e: mara_basile@yahoo.com.ar.

iii CONICET y Museo Etnográfico J. B. Ambrosetti, Universidad de Buenos Aires, Moreno 350 (1091), Ciudad Autónoma de Buenos Aires, Argentina. Correo-e: anitafeely@yahoo.com.ar

Recibido: Julio 2011 Revisado: Enero 2012 Aceptado: Marzo 2012. 
promote, maintain and strengthen the socio-economic, political and ideological relations that characterized the cultural development from the late Archaic to the Inca occupation in these areas. In this paper we focus on one of these routes traveled by the first agro pastoralist societies, generically referred to as formative or pre-late, who occupied this region between approximately 200 and 1.200 years A.D. We analyze some technological and visual aspects of the ceramic material recovered from archaeological sites located within the contrasting environments connected by this route. We then relate these results with the architectural characteristics of the sites of provenance of the ceramic samples. Finally, we discuss the existence of a tradition that is reproduced in time by building a space through the memory.

Key words: Connecting routes, Pre-late Societies, Pottery, Architecture, NorthWest Argentina.

\section{INTRODUCCIÓN}

Las diferentes líneas de investigación que se desarrollan dentro del proyecto arqueológico Chaschuil-Abaucán, PAChA (Ratto 2007), realizado en el Noroeste Argentino, específicamente en la provincia de Catamarca (Figura 1), interrelacionan la arqueología, la historia, las ciencias físicoquímicas y las naturales. Esto se orienta a conocer la complementariedad e integración de distintas ecozonas de la región -valle mesotérmico, puna transicional y cordillera-, pero no sólo apuntando a su diversidad ecológica, sino identificando las rutas por donde circuló información para consolidar las relaciones sociales, económicas y políticas a nivel regional (Berenguer 1994). En este marco, las investigaciones no se restringen a un lapso en particular porque consideramos que la dinámica cultural sólo puede ser aprehendida a través de lineamientos teórico-metodológicos que den cuenta de los procesos de cambio y de los mecanismos actuantes para determinar qué prácticas pervivieron, se transformaron o se perdieron en el tiempo. En este contexto es importante tener en cuenta que La Troya e inmediaciones, emplazada en el sector meridional del bolsón de Fiambalá (1.450 m.s.n.m.), fue un área de producción de alfarería para las sociedades pre-estatales y estatales que proveyeron de objetos cerámicos a las instalaciones emplazadas en las distintas ecozonas de la región abordadas en este trabajo (Ratto et al. 2004, 2008; entre otros). 


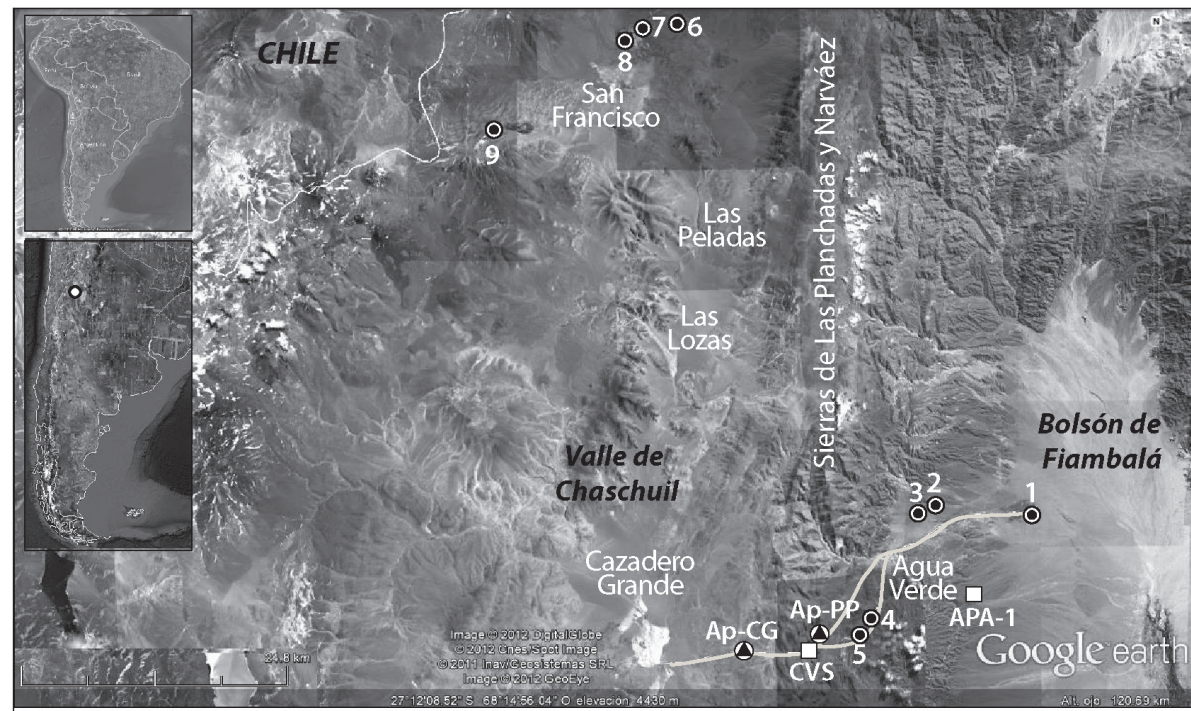

Referencias:

1: Palo Blanco (1.900 m.s.n.m); 2: Ranchillos2 (2.390 m.s.n.m); 3: Ojo del Agual (2.479 m.s.n.m); 4: Los Horcones (2.485 m.s.n.m); 5 : El Potrerillo (2.925 m.s.n.m); 6: Laguna Salada (4.000 m.s.n.m); 7: El Corral (4.000 m.s.n.m); 8: El Zorro (4.050 m.s.n.m); 9: Fiambalá1(5.000 m.s.n.m). APA-1: Alero Peña Abajo1; CVS: Cueva La Salamanca

Ap-PP: apacheta Piedra Parada; Ap-CG: apacheta Portezuelo cazadero Grande

Figura 1: Ubicación de los sitios arqueológicos de procedencia de la materialidad cerámica y arquitectónica del oeste tinogasteño analizados en este trabajo.

Figure 1: Location of the archaeological sites of provenience of the ceramic sherds and architectural features analyzed on this paper (West Tinogasta).

Nos enfocamos dentro del rango temporal que cubre el lapso definido entre los 200 y 1.200 años de nuestra era, encuadrándose dentro del período Formativo, con la salvedad de que en nuestra región su amplitud se extendió en el tiempo, desafiando los modelos de periodización vigentes para el noroeste argentino (en adelante NOA) catamarqueńo (Ratto et al. 2004). Consideramos que el Formativo constituye un proceso social, económico y político de larga data y amplia distribución espacial en el NOA. El proceso se materializa en prácticas concretas de producción y reproducción de personas, materiales, energía e información, que dieron como resultado “modalidades regionales" caracterizadas por la variabilidad artefactual y ambiental propia de cada ecozona: (a) diferentes patrones de asentamiento de las instalaciones con uso residencial, rural (puesto) y ceremonial; (b) la presencia de un amplio conjunto cerámico representado por diversos tipos y estilos decorativos; (c) la ocupación y/o explotación de diferentes pisos ecológicos desde los fondos de valle hasta la puna y las áreas cordilleranas, y (d) las relaciones con sociedades trasandinas. 
Estas características también se observan en el oeste catamarqueño ya que los pisos altitudinales de fondo de valle, precordillera, puna transicional y cordillera fueron ocupados por sociedades formativas en forma continua o interrumpida entre los años 200 y 1.200 de nuestra era, manifestándose en distintos tipos de instalaciones de residencia permanente, estacional o temporaria. Las diferentes planificaciones del espacio construido variaron en escala, materiales y técnicas constructivas, pero guardaron similitud respecto de sus organizaciones socio-espaciales (Ratto et al. 2008, Salminci 2005); además se reprodujeron distintas elecciones técnicas para la adquisición y tratamiento de las materias primas destinadas a la manufactura de piezas cerámicas (Feely y Ratto 2009, Feely 2010, entre otros).

En este contexto el aporte de este trabajo consiste en profundizar en el análisis de otros indicadores que dan cuenta de la integración de las tierras bajas (valle) y altas (puna transicional, pre-cordillera y cordillera) durante el lapso considerado (200 al 1.200 AD) para revelar la existencia de códigos compartidos que se manifiestan en los modos similares de hacer las cosas (Lemonnier 2002). Nos enfocamos en el análisis de determinadas elecciones técnicas implementadas en la producción de objetos cerámicos y la construcción de los cimientos y muros de los sitios arqueológicos emplazados dentro de la extensa ruta que permite articular las tierras bajas y altas del oeste tinogasteño. Esto se logra a través del tránsito por conectores naturales (quebradas, abras, portezuelos) que vinculan el sector norte del bolsón de Fiambalá (1.900 m.s.n.m.), la pre-cordillera occidental (2.4003.500 m.s.n.m.), la puna transicional del valle de Chaschuil (3.500-4.400 m.s.n.m.), y los ambientes altoandinos de la alta cordillera de Los Andes (4.400-6.730 m.s.n.m.). Los sitios emplazados en las diferentes ecozonas que recorren esta extensa ruta tuvieron diferentes funciones: (i) residenciales (aldeas o caseríos de ocupación anual); (ii) estacionales, como puestos para el desarrollo de actividades productivas, y (iii) temporarios, destinados a actividades específicas, especialmente la caza de camélidos silvestres.

\section{Antecedentes}

Los amplios territorios del oeste catamarqueño están surcados por formaciones montañosas con sentido norte-sur. De este modo los ambientes pre-cordilleranos y de valles altos se ubican dentro de los espacios delimitados por los grandes cordones montañosos. Éstos son, de oeste a este: la cordillera de Los Andes, las Sierras de Las Planchadas y Narváez y las Sierras de Fiambalá, encontrándose las tierras altas de la puna transicional de 
Chaschuil (3.000-4.000 m.s.n.m.) y los valles altos del bolsón de Fiambalá (1.500-2.000 m.s.n.m.) dentro de estos grandes ejes longitudinales.

El paisaje arqueológico de las tierras altas de la puna transicional y cordillera da cuenta de un enorme rango de variación en su forma y estructura espacio-temporal. Cuenta con evidencias de ocupación desde sociedades con economías extractivas hasta el advenimiento del control incaico, presentando artefactos y estructuras en densidades, distribuciones y diversidades diferenciales (Ratto 2000, 2003). Así, los paisajes dan cuenta de cambios en el uso del espacio a través del tiempo por parte de las sociedades que exploraron, explotaron, transitaron y habitaron estas tierras altas. El espacio se ocupó en forma discontinua a lo largo del tiempo, independientemente del tipo de economía, organización social y política de los grupos. La estructura del registro arqueológico permitió perfilar a la región como un posible corredor de comunicación con el bolsón de Fiambalá. Otro aspecto interesante de esta área es el rol cumplido por la caza de camélidos silvestres a lo largo del tiempo llegando a nuestros días (Ratto y Orgaz, 2008).

Por otro lado, las manifestaciones culturales del valle mesotérmico no cuentan aún con una profundidad temporal tan amplia como las de las tierras altas. Esto, en parte es producto de que las investigaciones se reanudaron luego de 40 años de inactividad, después de la interrupción de los trabajos pioneros realizados a fines de la década de 1970 (González y Sempé 1975, Sempé 1976), dando como consecuencia que algunas áreas no cuentan todavía con trabajos prospectivos. Las nuevas líneas de investigación se abocaron al estudio del proceso de cambio cultural y ambiental que se materializa en los paisajes arqueológicos que se suceden o superponen en el tiempo, principalmente de las sociedades pre-tardías e incas. Para ello se realizaron estudios arqueométricos sobre cerámica -morfotecnológicos, petrográficos y de procedencia-, visuales, arqueogeofísicos, arquitectónicos y paleoambientales, entre otros. Éstos se complementaron con el estudio de las rutas que interconectaron el valle mesotérmico con la puna transicional y la cordillera andina (Basile 2011, Basile y Ratto 2010, Bonomo et al. 2010, Feely 2010, Ratto 2006, 2007; Salminci 2005, entre otros).

De acuerdo con los fines de este trabajo, es importante destacar que las áreas cordillerana, puneña, precordillerana y valles altos presentan diferencias no sólo en los tipos de instalaciones, sino también en los procesos de formación que inciden directamente sobre las construcciones y el contenido material. En las tierras altas puneñas y cordilleranas los sitios 
presentan alta visibilidad, pero estuvieron sujetos a reclamaciones en tiempos prehispánicos y actuales; además, el material cerámico está ausente, en estado muy fragmentario o presenta alta meteorización. Por su parte, en la precordillera y cordillera se registraron contextos reclamados como puestos para el pastoreo de ganado europeo, además del registro de intensos procesos de acumulación por acción eólica (alta tasa de sedimentación), por lo que no se descarta la existencia de otros sitios sepultados por los médanos. Por último, en el valle alto es donde se registraron las instalaciones residenciales permanentes y la mayor densidad y diversidad de material cerámico. Esta ecozona fue y es afectada por la acción fluvial, aluviones y por la formación de grandes medanales.

\section{RUTAS CONECTORAS DE ECOZONAS Y MATERIALIDAD}

Ratto (2006) relevó y documentó varias sendas y conectores naturales que posibilitan y facilitan la integración entre diferentes ecozonas de la región. El relevamiento permitió incluir dentro de una extensa red de comunicación espacial tanto los sitios arqueológicos conocidos, como los nuevos registrados durante el desarrollo de los trabajos. Estas rutas funcionan como corredores que estructuran el espacio en sentido norte-sur, permitiendo en distintos puntos empalmar con otras de recorrido transversal (este-oeste) para acceder al área puneña transicional y la alta cordillera de Los Andes. ${ }^{1}$ En este trabajo presentamos únicamente las referencias arqueológicas asociadas con dos de las tres rutas transversales (este-oeste). A saber:

a) Ruta río Abajo: comienza en la cota de 1.850 m.s.n.m. del bolsón de Fiambalá remontando la quebrada del río en dirección oeste y sudoeste hasta llegar al área del río Pie de La Cuesta (3.300 m.s.n.m.), ubicado en la ladera oriental de las Sierras de Las Planchadas y Narváez. En este punto empalma con el recorrido de la ruta que se transcribe a continuación.

b) Ruta por los ríos Agua de la Cañada y La Cuesta: esta ruta tiene una extensión de $54 \mathrm{~km}$ en el segmento comprendido desde Palo Blanco (1.900 m.s.n.m.) en el bolsón de Fiambalá hasta la vega de altura de Cazadero Grande (3.405 m.s.n.m.) en la puna transicional, extendiéndose unos $70 \mathrm{~km}$ más hasta llegar a los ambientes altoandinos cordilleranos limítrofes con Chile. Para ello se remonta el río Agua de la Cañada hasta el paraje Agua Verde (2.780 m.s.n.m.), se gira al sursuroeste atravesando la quebrada de Los Molles, Campo del Agua del Toro y Campo de Iruchal para empalmar con el río de la Cuesta. Se cruza las Sierras de Las Planchadas y Narváez por una senda en ziz-zag (3.300 a 3.800 m.s.n.m.), 
encontrándose marcada la cima por la apacheta Piedra Parada. Luego se atraviesa la vega Los Alojos (3.730 m.s.n.m.) siguiendo en dirección oeste para llegar al Portezuelo de Cazadero Grande (4.135 m.s.n.m.) donde se emplaza otra apacheta. Este espacio marcado es un punto nodal, ya que a partir de aquí pueden seguirse dos rutas para comunicar el piso puneńo con el altoandino:

i. Continuar en dirección oeste descendiendo por una quebrada angosta y empinada, denominada por los lugareños como Callejón de Cazadero Grande, para llegar al sector sur de la vega de altura homónima (3.405 m.s.n.m.) (Figura 1). Desde aquí, a través de la quebrada de Cazadero Grande, previo cruce de su vega y de las pampas de altura que la rodean, se logra la comunicación con distintas áreas de la Cordillera de Los Andes y los espacios trasandinos donde se han registrado sitios arqueológicos que no se consideran en este trabajo. ${ }^{2}$

ii. Continuar en dirección norte desplazándose por los filos de las Sierras de Las Planchadas y Narváez accediendo a distintos parajes de la puna transicional, como las vegas de Las Lozas (3.800 m.s.n.m.); Las Planchadas (3.900 m.s.n.m.) y de San Francisco (4.000 m.s.n.m.) (Figura 1). Desde la primera es también posible acceder a los pisos altoandinos y cordilleranos del occidente a través de la quebrada de Las Lozas, habiéndose registrado sitios arqueológicos (Ratto et al. 2002, Ratto 2003) que tampoco se incluyen aquí. ${ }^{3}$

Los sitios arqueológicos que conforman la base de este trabajo son los emplazados en estas dos rutas ${ }^{4}$ transversales que permiten la articulación del sector alto del valle mesotérmico de Fiambalá (1.900 m.s.n.m.) con la puna transicional de Chaschuil a la altura del paraje Cazadero Grande (3.400/3.500 m.s.n.m.), para luego conectar con los sitios de los ambientes de puna transicional (4.000 m.s.n.m.) y altoandino (5.000 m.s.n.m.) (Figura 1). En estos recorridos las manifestaciones arquitectónicas, rupestres y los conjuntos cerámicos registrados fueron:

a) La localidad arqueológica de Palo Blanco (1.900 m.s.n.m.), aldea o caserío pre-tardío emplazado en el bolsón de Fiambalá (Sempé 1976, Ratto 2007, Bonomo et al. 2010) con fechados radiocarbónicos que la ubican temporalmente entre los años 200 y 900 de nuestra era aproximadamente (Tabla 1).

b) Ojo del Agua 1 (2.479 m.s.n.m), Los Horcones (2.845 m.s.n.m) y El Potrerillo (2.925 m.s.n.m) se emplazan en la precordillera 
habiendo sido interpretados como puestos de pastoreo (Ratto, 2006; Ratto et al., 2008; Feely y Ratto, 2009). Están asociados mayoritariamente a cerámica pre-tardía, contándose sólo en el primer caso con fechado radiocarbónico (Tabla 1).

c) Apachetas en los pasos o abras que permiten el acceso a diferentes ecozonas asociados a los puntos de mayor altitud del recorrido -Cordillera de Narváez y Portezuelo de Cazadero Grande-, no habiéndose recuperado material cerámico en asociación (Ratto 2006).

d) Hallazgos aislados o concentraciones discretas de material cerámico recuperado en depresiones colmatadas por sedimentos de origen eólico (Ratto 2006).

e) Sitios con pinturas (Cueva La Salamanca) y grabados (Alero Peña Abajo 1) rupestres, próximos o asociados directamente al recorrido, donde se registraron representaciones asignables cronológicamente a momentos pre-tardíos. Los sitios no presentaron material cerámico en superficie (Ratto 2006, Basile y Ratto 2010).

f) Los sitios Laguna Salada (4.000 m.s.n.m), El Corral (4.000 m.s.n.m.) y El Zorro (4.050 m.s.n.m.) emplazados en ambiente de puna transicional. Están conformados por estructuras adosadas o aisladas, de forma subcircular, con muros bajos de pirca seca sin techar, los que se construyeron dentro o en las inmediaciones de formaciones rocosas. Todos presentan cerámica pretardía y se ubican cronológicamente entre los años 478 al 1165 de la era (Tabla 1) (Ratto et al. 2002).

g) El sitio Fiambalá 1 (5.000 m.s.n.m.) está emplazado en ambiente altoandino en plena cordillera de Los Andes, tratándose de un sitio multicomponente asociado a la ruta de ascenso al volcán Incahuasi. Presenta ocupaciones transitorias pero recurrentes sin registro de material cerámico pero con tecnofacturas (techos y cordeles de fibra vegetal, vigas de madera, entre otros). Su función se relaciona con prácticas rituales realizadas entre los años 530-720 y 1410-1470 de la era correspondiendo a momentos pretardíos e incaicos, respectivamente (Tabla 1) (Kligmann y Ratto 2009, Ratto y Orgaz 2009, Ratto y De Nigris 2012, entre otros). 


\begin{tabular}{|c|c|c|c|c|c|c|}
\hline Eco-zona & \multicolumn{2}{|c|}{$\begin{array}{l}\text { Localidad o sitio } \\
\text { arqueológico }\end{array}$} & $\begin{array}{c}\text { Sigla } \\
\text { laboratorio }\end{array}$ & Material & $\begin{array}{c}\text { Ańos } \\
\text { radiocarbónicos }\end{array}$ & $\begin{array}{c}\text { Ańos } \\
\text { calendáricos } \\
\text { calibrados }\end{array}$ \\
\hline \multirow{6}{*}{$\begin{array}{c}\text { Valle alto } \\
\text { (1.900 m.s.n.m.) }\end{array}$} & \multirow{6}{*}{$\begin{array}{l}\text { Palo } \\
\text { Blanco }\end{array}$} & \multirow{2}{*}{$\mathrm{NH}-1$} & AC365 & carbón & $1760 \pm 95^{*}$ & $209-388$ \\
\hline & & & AC366 & carbón & $1640 \pm 100^{*}$ & $324-536$ \\
\hline & & \multirow{2}{*}{$\mathrm{NH}-3$} & AA65138 & carbón & $1566 \pm 39$ & $458-535$ \\
\hline & & & AA65139 & carbón & $1467 \pm 39$ & $596-639$ \\
\hline & & \multirow{2}{*}{$\mathrm{NH}-6$} & AA81735 & carbón & $1236 \pm 37$ & $685-882$ \\
\hline & & & AA81736 & carbón & $1194 \pm 37$ & $800-882$ \\
\hline \multirow{3}{*}{$\begin{array}{c}\text { Precordillera } \\
(2.400-2.900 \\
\text { m.s.n.m.) }\end{array}$} & \multicolumn{2}{|c|}{ Ojo del Agua 1} & AA89937 & carbón & $990 \pm 45$ & $994-1047$ \\
\hline & \multicolumn{2}{|c|}{ Potrerillo 1,2 y 3} & \multicolumn{4}{|c|}{ Adscripción pre-tardía por conjunto cerámico } \\
\hline & \multicolumn{2}{|c|}{ Los Horcones } & \multicolumn{4}{|c|}{ Adscripción pre-tardía por conjunto cerámico } \\
\hline \multirow{4}{*}{$\begin{array}{l}\text { Puna transicional } \\
\text { (4.000 m.s.n.m.) }\end{array}$} & \multicolumn{2}{|c|}{ Laguna Salada } & UCTL1316 & cerámica & $1315 \pm 130$ & $555-815$ \\
\hline & \multicolumn{2}{|c|}{ El Zorro } & AA89935 & carbón & $1604 \pm 49$ & $478-534$ \\
\hline & \multirow{2}{*}{\multicolumn{2}{|c|}{$\begin{array}{l}\text { El Corral** } \\
\text { UCTL1314 }\end{array}$}} & UCTL1315 & cerámica & $1265 \pm 120$ & $615-855$ \\
\hline & & & cerámica & $925 \pm 90$ & $985-1165$ & \\
\hline \multirow{2}{*}{$\begin{array}{l}\text { Alta cordillera } \\
(5.000 \text { m.s.n.m.) }\end{array}$} & \multirow{2}{*}{\multicolumn{2}{|c|}{$\begin{array}{l}\text { Fiambalá } 1^{* * *} \\
\text { AA69976 }\end{array}$}} & AA81740 & carbón & $1499 \pm 51$ & $534-636$ \\
\hline & & & carbón & $1294 \pm 33$ & $680-722$ & \\
\hline \multicolumn{7}{|c|}{$\begin{array}{l}\text { * Realizados por la Dra. M.C. Sempé e informados por Gordillo (1999). Se aclara que de Palo Blanco } \\
\text { se utilizan solo los fechados que corresponden a los núcleos habitacionales de procedencia de la muestra } \\
\text { cerámica analizada. } \\
{ }^{* *} \text { El conjunto cerámico del sitio SF-04 ( } 4.558 \text { m.s.n.m.), emplazado en ambiente altoandino, no } \\
\text { es considerado en este trabajo pero guarda características tecno-morfo-estilísticas similares a las } \\
\text { del conjunto analizado. Una reciente datación radiocarbónica aportó una fecha de } 1059 \pm 34 \text { A.P. } \\
\text { (AA93281, óseo, } 1 \text { sigma) que es coincidente con el fechado más tardío obtenido por TL. } \\
\text { ***Los fechados radiocarbónicos de tiempos incaicos son } 465 \pm 34 \text { AP (AA69977), } 504 \pm 36 \text { AP } \\
\text { (AA81739) y } 458 \pm 49 \text { AP (AA81741). }\end{array}$} \\
\hline
\end{tabular}

Tabla 1: Fechados absolutos de sitios arqueológicos pre-tardios por ecozona de emplazamiento Table 1: Absolute dating of pre-late archaeological sites by eco-zone. 


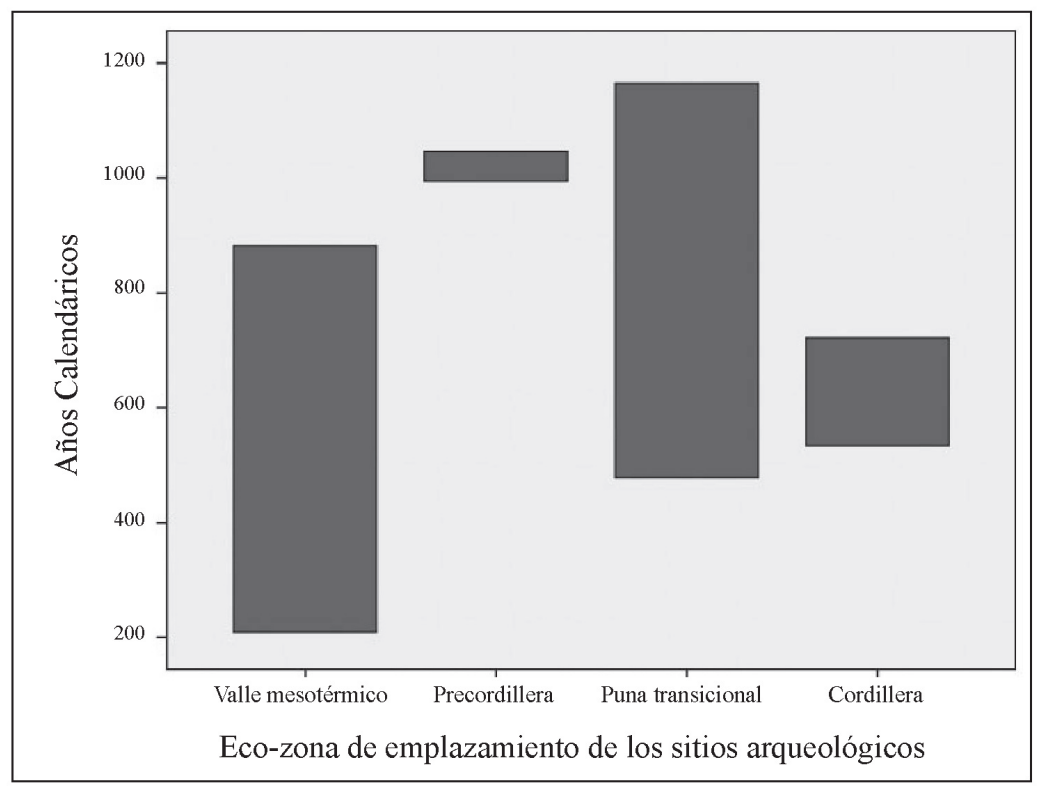

Figura 2: Fechados radiocarbónicos calibrados de sitios arqueológicos pre-tardios por ecozona de emplazamiento.

Figure 2: Calibrated radiocarbon dates of pre-late archaeological sites by eco-zone.

De acuerdo con lo expuesto, distintos tipos de instalaciones se emplazaron dentro de las rutas que conectaron los ambientes contrastantes del oeste tinogasteño (valle alto, precordillera, puna transicional y altoandino). Estos espacios fueron ocupados entre los 200 y 1.200 años de la era por grupos cuya cultura material remite a tiempos Formativos, recordando que en nuestra región de estudio este modo de vida se extiende en el tiempo más allá de los límites fijados por la periodización vigente para el NOA catamarqueńo (Tabla 1 y Figura 2).

\section{Metodología}

La muestra de material cerámico está conformada por fragmentos decorados que han podido ser adscriptos a formas de vasijas y que provienen de los sitios emplazados en los distintos ambientes articulados por la ruta presentada, con excepción de Fiambalá 1 y El Corral; ya que en el primero no se produjeron hallazgos de material cerámico, mientras que en el segundo, la muestra presentó un alto grado de fragmentación imposibilitando la realización de los análisis requeridos para alcanzar los objetivos propuestos. 
Trabajar con conjuntos fragmentarios impone limitaciones difíciles de superar sin mediar razonamientos analógicos basados en el registro de regularidades en piezas enteras. Los procesos de manufactura se desarrollan en distintas etapas que generan indicadores arqueológicos. Sin embargo, sólo consideramos aquellos que pueden ser transformados en una escala ordinal jerárquica para su posterior tratamiento estadístico multivariado (ver más adelante). A saber:

a) Formas de las piezas: esta variable está limitada por los sesgos que impone el análisis de materiales fragmentarios. La muestra analizada da cuenta de distintos segmentos de piezas que corresponden a bordes, cuerpos y bases; combinándose dos criterios para la clasificación de las formas. Por un lado, se consideraron los tiempos o etapas invertidas en levantar las piezas; por el otro, teniendo en cuenta la eversión de las paredes, se contempló el grado de accesibilidad a los contenidos. De esta manera, se generaron tres categorías de formas de piezas inferidas a partir del análisis del material fragmentario: (i) piezas levantadas en un tiempo que presentan paredes fuertemente divergentes y corresponden a formas muy abiertas (escudillas y platos), (ii) piezas también levantadas en un tiempo, pero que poseen paredes medianas a ligeramente divergentes y corresponden a formas abiertas (pucos y vasos) y (iii) piezas levantadas en dos tiempos que corresponden a formas cerradas (ollas y jarros). Para la asignación de los fragmentos a una categoría se procedió a su orientación y a la identificación de su ubicación espacial en la pieza completa, teniendo en cuenta la presencia de evidencias de técnicas de manufactura (orientación de rodetes y alisado), espesor y curvatura de las paredes. Asimismo, se consideró la presencia y ausencia de decoración y pulido interno a fines de diferenciar las piezas levantadas en una o dos etapas.

b) Pastas cerámicas: el registro de esta variable resulta, en contraste, poco condicionado en el caso de muestras fragmentarias. Para su clasificación se procedió a la inspección por lupa trinocular de un corte fresco de la totalidad de los fragmentos analizados, registrándose la densidad, el tamańo, la forma y el tipo de antiplástico. La combinación de estos elementos determina distintas texturas de pasta que varían desde muy finas a muy gruesas; en nuestro caso se identificaron seis grupos diferentes cuyas características se resumen en la Tabla 2. 


\begin{tabular}{|c|c|c|c|c|c|}
\hline \multirow{2}{*}{$\begin{array}{l}\text { Grupo de } \\
\text { pasta }\end{array}$} & \multicolumn{4}{|c|}{ Antiplástico } & \multirow{2}{*}{$\begin{array}{l}\text { Textura de la } \\
\text { pasta }\end{array}$} \\
\hline & Densidad (\%) & Tamaño predominante & Forma & Tipo & \\
\hline I & $0<10$ & Muy fino/fino & Redondeada & $\begin{array}{l}\text { Cuarzo, } \\
\text { litoclastos no } \\
\text { identificados, } \\
\text { mica, plagioclasa }\end{array}$ & Muy fina \\
\hline II & $\geq 10<20$ & Muy fino/fino & Redondeada & ídem & Muy fina/ fina \\
\hline III & $\geq 20<30$ & Muy fino/fino & Redondeada & ídem & Fina/ media \\
\hline IV & $\geq 30$ & Muy fino/fino & $\begin{array}{l}\text { Angular/ } \\
\text { redondeada }\end{array}$ & ídem & Media \\
\hline $\mathrm{V}$ & $\geq 10<30$ & Medio & $\begin{array}{l}\text { Angular/ } \\
\text { redondeada }\end{array}$ & $\begin{array}{l}\text { Cuarzo, } \\
\text { fragmentos de } \\
\text { roca graníticos, } \\
\text { volcánicos, } \\
\text { plagioclasa, mica }\end{array}$ & Media/gruesa \\
\hline VI & $\geq 10<30$ & Grueso & $\begin{array}{l}\text { Angular/ } \\
\text { redondeada }\end{array}$ & ídem & $\begin{array}{l}\text { Gruesa/ muy } \\
\text { gruesa }\end{array}$ \\
\hline
\end{tabular}

Tabla 2: Características tecnológicas de los grupos de pastas cerámicas.

Table 2: Technological characteristics of ceramic paste groups.

c) Técnicas de resolución visual: esta variable es el resultado de la combinación del tipo de tratamiento (alisado o pulido) y de las técnicas decorativas (acanalado, pulido en líneas, inciso, grabado, pintura y/o modelado) implementadas en las superficies de cada uno de los fragmentos analizados. Todas estas técnicas implican el uso de instrumentos o sustancias particulares (cantos rodados, puntas, pinceles, pigmentos, entre otros) en momentos de ejecución específicos. Su combinación pone en juego conocimientos y habilidades particulares, permitiendo ordenar jerárquicamente los estados de esta variable en función del grado de control requerido por los tiempos, los instrumentos, los elementos y la cantidad de operaciones necesarias para la implementación de las técnicas que inciden en el producto terminado.

d) Representaciones plásticas: su análisis es el más afectado por el estado fragmentario de la muestra en estudio. Sin embargo, esta limitación se superó utilizando los parámetros definidos a partir del análisis de las imágenes documentadas en las piezas enteras procedentes de la región de Fiambalá, junto con las regularidades tecno-morfo-estilísticas derivadas de los estudios conducidos por otros investigadores a nivel regional y extraregional (Sempé 1977, Balesta 2000, Gordillo 2009, entre otros). Cada una de las representaciones constituye la unidad de entrada a partir de la cual estructuramos la base de datos para proceder al análisis. En esta dirección, 
el primer paso fundamental fue la identificación y clasificación de estas imágenes. Para ello se utilizó como base la propuesta de clasificación en categorías de conjuntos de clases, clases y subclases de representaciones elaborada por Aschero $(2006,2012)$ para el estudio del arte rupestre de la vecina región de Antofagasta de la Sierra (ANS). Estas categorías constituyen variables cualitativas que no pueden ordenarse jerárquicamente en términos de inversión de trabajo o incremento de complejidad y, por lo tanto, no se consideran en el análisis multivariado. Sin embargo, aquí consideramos que todas estas representaciones están compuestas por un número determinado de elementos mínimos que denominamos unidades morfológicas (UM) (sensu Aschero 1975) y que remiten a una intención gestual particular. En esta dirección hemos definido ocho tipos de unidades morfológicas básicas (puntos, trazos rectilíneos, angulares, libremente ondulados, curvilíneos simples, en gancho, espiralados y elementos plásticos) sobre la base de los trabajos de Kandinsky ([1926] 2007), Scott ([1951] 1962) y Aschero $(1975,2012)$. Éstas pueden presentarse en forma aislada pero, en general, la definición de las representaciones resulta de la combinación de una única unidad en sí misma, o de más de una de ellas. Para dar cuenta de esta variabilidad generamos un número binario que expresara la presencia y la ausencia de cada una de las UM definidas en cada una de las imágenes de la muestra analizada (Basile y Ratto 2010, 2011; Basile 2011). Luego, a cada una de las 25 combinaciones expresadas en números binarios registradas en esta muestra, se les asignó una ubicación específica y jerárquica dentro del total de las combinaciones posibles, que ascienden a 255 sobre la base de las ocho UM básicas definidas. Por otro lado, a fin de analizar la forma en que estas unidades se articulan entre sí para configurar cada una de las imágenes registradas, se definieron diferentes tipos de articulaciones sobre la base de los trabajos de Gardin (1978) y Aschero (2012), generándose ocho estados que dan cuenta de los tipos de articulaciones básicas (aditiva, simétrica e inscripta) y de sus combinaciones, aclarando que la ausencia de articulación también se considera como un estado para esta variable.

Todas las variables cualitativas (forma de la pieza, pasta cerámica, técnica de resolución visual, combinación de unidades morfológicas y tipo de articulación) fueron transformadas a variables ordinales siguiendo una secuencia lógica para su ordenamiento jerárquico, aplicando criterios que dan cuenta del incremento progresivo en la inversión de trabajo (sensu Fiore 2007) o de las texturas de las pastas -(ver más arriba). Esta transformación permitió realizar un tratamiento estadístico multivariado aplicando un conjunto de técnicas combinando métodos factoriales y de análisis de conglomerados, los 
que consistieron en Análisis de Correspondencia Múltiple (ACM) y Análisis de Conglomerados Jerárquicos (ACJ) -Método Ward-, respectivamente.

Finalmente, la metodología para el análisis arquitectónico se basa en las características de muros y cimientos para comparar las técnicas utilizadas en la fundación de los sitios emplazados dentro de los ambientes articulados por la ruta. Para ello se sigue la propuesta elaborada por Salminci (2005) considerando la materia prima y la morfometría, la preparación, la ubicación y la colocación de los materiales utilizados en la construcción.

\section{Resultados}

Organizamos nuestros resultados en dos ámbitos diferentes que son presentados a continuación: definición de los modos de hacer los objetos cerámicos y características de los conjuntos arquitectónicos.

\section{Definición de los modos de hacer los objetos cerámicos}

La muestra cerámica se compone de 615 fragmentos procedentes de los distintos sitios arqueológicos que se emplazan dentro de la ruta que comunica el piso de 1.900 m.s.n.m. con las tierras altas puneńas y cordilleranas (ver más arriba) (Figura 3). Dicha muestra procede de los núcleos habitacionales No 1, 3 y 6 de la localidad arqueológica de Palo Blanco, de los sitios Ojo del Agua 1, Los Horcones, El Potrerillo, Laguna Salada, El Zorro y los hallazgos aislados recuperados durante el trayecto, ya que de las intervenciones realizadas en Fiambalá 1 no se recuperó esa clase de material. Las características tecno-morfo-estilísticas de la muestra se corresponden con las características que guarda la alfarería de momentos formativos dentro del NOA catamarqueño. En la Tabla 3 presentamos el conjunto cerámico en función de las variables consideradas. Al respecto, se observa que la mayor diversidad de pastas cerámicas, técnicas de resolución visual, combinación de UM y tipos de articulación se registra en los materiales procedentes de la aldea de Palo Blanco, mientras que las mismas formas de piezas están presentes en todos los sitios de la muestra. 


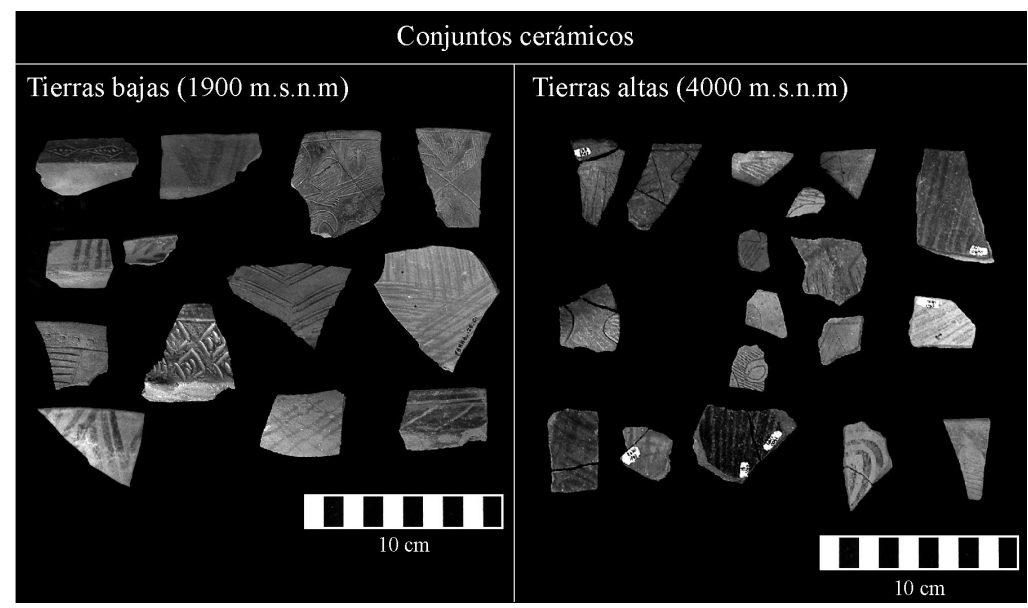

Figura 3: Conjunto cerámico procedente de los sitios de las tierras bajas y altas emplazados en la ruta analizada

Figure 3: Ceramic sherds from lowlands and highlands archaeological sites located on the analyzed route.

A través del tratamiento numérico multivariado se generaron tres grupos distintivos (Figura 4). A saber:

a) En el grupo No 1 (266:615) predominan: (i) piezas abiertas y cerradas; (ii) pastas de texturas muy finas; (iii) técnica de resolución visual de pulido en líneas sobre superficies pulidas; (iv) representaciones visuales resueltas por medio de la combinación de la unidad morfológica de trazos lineales, y (v) que se resuelven a través de la articulación aditiva o se presentan en forma aislada.

b) En el grupo No 2 (227:615) predominan: (i) piezas abiertas y muy abiertas; (ii) pastas muy finas; (iii) la técnica de resolución visual de incisión sobre superficies pulidas; (iv) diseños plasmados empleando la combinación de unidades morfológicas de puntos y trazos lineales, y (v) que se resuelven a partir de la fusión de las articulaciones simétrica e inscripta.

c) Por último, en el grupo No 3 (122:615) predominan: (i) piezas muy abiertas y abiertas; (ii) pastas de texturas muy fina/fina y fina/media; (iii) técnica de resolución visual de pulido en líneas sobre superficies pulidas; (iv) representaciones visuales resueltas por medio de la combinación de la unidad morfológica de trazos lineales, y (v) que se resuelven a través de la articulación aditiva o se presentan en forma aislada. 


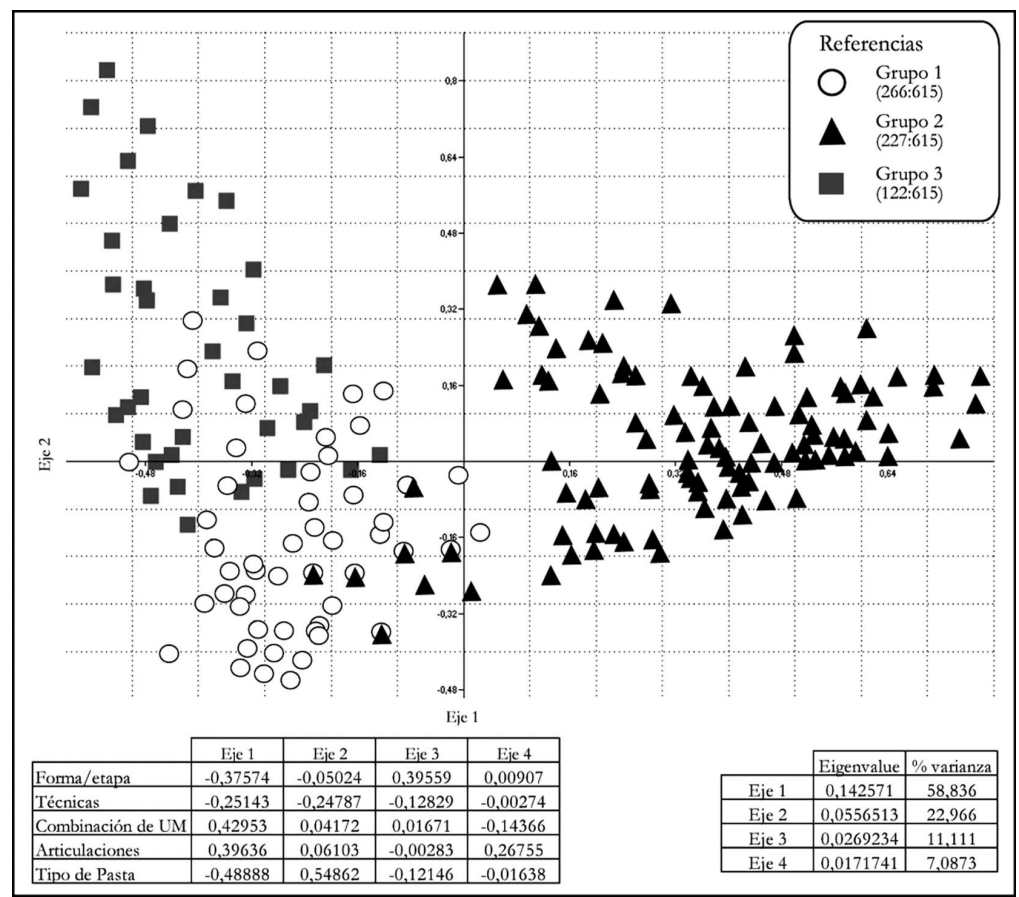

Figura 4: Gráfica del Análisis de Correspondencia Múltiple en función de los grupos de material cerámico pronosticados estadísticamente por Análisis de Conglomerados Jerárquicos.

Figure 4: Graph of Multiple Correspondence Analysis of ceramic material groups predicted statistically by Hierarchical Cluster Analysis.

El tratamiento multivariado indica que los grupos $\mathrm{N}^{\circ} 1$ y $\mathrm{N}^{\circ} 2$ están representados por materiales que proceden de sitios emplazados en todas las ecozonas que conecta la ruta; mientras que el grupo No 3 es exclusivo de la instalación residencial permanente de Palo Blanco localizada en el valle alto (Tabla 4 y Figura 5). Estos son los materiales que provienen del núcleo habitacional No 6 que se caracterizan por presentar mayor inversión de trabajo que se manifiesta en la cantidad de operaciones, instrumentos y elementos involucrados en la aplicación de las técnicas de resolución visual, como así también, en la combinación de una mayor cantidad de unidades morfológicas y tipos de articulaciones. 


\begin{tabular}{|c|c|c|c|c|c|c|c|}
\hline \multirow{2}{*}{$\begin{array}{l}\text { Sitios } \\
\text { arqueológicos }\end{array}$} & \multicolumn{7}{|c|}{ Variables tecnomorfológicas y visuales del conjunto cerámico } \\
\hline & \begin{tabular}{|l|}
$\begin{array}{l}\text { Forma } \\
\text { pieza }\end{array}$ \\
$\mathrm{MA}=82$ \\
\end{tabular} & \begin{tabular}{|l|}
$\begin{array}{l}\text { Pasta } \\
\text { cerámica }\end{array}$ \\
\end{tabular} & \multicolumn{2}{|c|}{$\begin{array}{l}\text { Técnicas resolución } \\
\text { visual }\end{array}$} & \multicolumn{2}{|c|}{$\begin{array}{l}\text { Combinación de unidades } \\
\text { morfológicas }\end{array}$} & \begin{tabular}{|l|}
$\begin{array}{l}\text { Tipos de } \\
\text { articulación }\end{array}$ \\
$\mathrm{Np}=194$ \\
$\mathrm{Ad}=52$
\end{tabular} \\
\hline $\begin{array}{l}\text { Palo Blanco } \\
\text {-NH1, } \\
\text { NH3, NH6- } \\
(314: 615)\end{array}$ & $\begin{array}{l}\mathrm{MA}=82 \\
\mathrm{~A}=149 \\
\mathrm{C}=83\end{array}$ & $\begin{array}{l}\mathrm{PI}=90 \\
\mathrm{PII}=101 \\
\mathrm{PIII}=53 \\
\mathrm{PIV}=24 \\
\mathrm{PV}=38 \\
\mathrm{PVI}=8\end{array}$ & $\begin{array}{l}\mathrm{Al} / \mathrm{Ac}=1 \\
\mathrm{Pu} / \mathrm{Ac}=1 \\
\mathrm{Pu} / \\
\mathrm{Pul}=145 \\
\mathrm{Al} / \mathrm{In}=40 \\
\mathrm{Pu} / \mathrm{In}=59 \\
\mathrm{Pu} / \mathrm{Gr}=13 \\
\mathrm{Al} / \mathrm{Pt}=9\end{array}$ & $\begin{array}{l}\mathrm{Pu} / \mathrm{Pt}=15 \\
\mathrm{Pu} / \mathrm{In}- \\
\mathrm{Pul}=29 \\
\mathrm{Pu} / \mathrm{Md}- \\
\mathrm{In}=1 \\
\mathrm{Al} / \mathrm{Pt}-\mathrm{Md}- \\
\mathrm{In}=1\end{array}$ & $\begin{array}{l}\text { No01=7 } \\
\text { No02=21 } \\
\text { No03=11 } \\
\text { No04=4 } \\
\text { No07=4 } \\
\text { No08=8 } \\
\text { No11=2 } \\
\text { Las No6, 1 } \\
\text { 22, 24 y 25 } \\
\text { una única v }\end{array}$ & $\begin{array}{l}\text { No09=32 } \\
\text { No12=2 } \\
\text { No13=6 } \\
\text { No15=2 } \\
\text { No18=2 } \\
\text { No21 }=4 \\
\text {, 16, 17, 19, 20, } \\
\text { se registraron } \\
\text { ez. }\end{array}$ & $\begin{array}{l}\mathrm{Np}=194 \\
\mathrm{Ad}=52 \\
\mathrm{Sm}=2 \\
\mathrm{Icp}=4 \\
\mathrm{Ad} / \mathrm{Icp}=43 \\
\mathrm{Sm} / \mathrm{Icp}=6 \\
\mathrm{Ad} / \mathrm{Sm} / \\
\mathrm{Icp}=13\end{array}$ \\
\hline $\begin{array}{l}\text { Ojo del Agua } 1 \\
(121: 615)\end{array}$ & $\begin{array}{l}\mathrm{MA}=36 \\
\mathrm{~A}=65 \\
\mathrm{C}=20\end{array}$ & $\mathrm{PI}=121$ & $\begin{array}{l}\mathrm{Al} / \mathrm{Ac}=1 \\
\mathrm{Pu} / \mathrm{Pul}=35 \\
\mathrm{Al} / \mathrm{In}=6 \\
\mathrm{Pu} / \mathrm{In}=50\end{array}$ & $\begin{array}{l}\mathrm{Pu} / \mathrm{Gr}=2 \\
\mathrm{Al} / \mathrm{Pt}=3 \\
\mathrm{Pu} / \mathrm{Pt}=13 \\
\mathrm{Pu} / \mathrm{In}- \\
\mathrm{Pul}=11\end{array}$ & $\begin{array}{l}N^{\circ} 01=2 \\
N^{\circ} 02=67 \\
N^{\circ} 03=8 \\
N^{\circ} 07=7 \\
\text { Las No 4, 1 } \\
\text { se registrar }\end{array}$ & $\begin{array}{l}\mathrm{N}^{\circ} 08=6 \\
\mathrm{~N}^{\circ} 09=20 \\
\mathrm{~N} 11=3 \\
\mathrm{No} 13=3 \\
2,14,20 \text { y } 23 \\
\text { n una única vez. }\end{array}$ & $\begin{array}{l}\mathrm{Np}=69 \\
\mathrm{Ad}=14 \\
\mathrm{Icp}=8 \\
\mathrm{Ad} / \mathrm{Sm}=1 \\
\mathrm{Ad} / \mathrm{Icp}=25 \\
\mathrm{Sm} / \mathrm{Icp}=4\end{array}$ \\
\hline $\begin{array}{l}\text { Hallazgos } \\
\text { aislados } \\
\text { conector } \\
(8: 615)\end{array}$ & $\begin{array}{l}\mathrm{MA}=4 \\
\mathrm{~A}=1 \\
\mathrm{C}=3\end{array}$ & $\mathrm{PI}=8$ & $\begin{array}{l}\mathrm{Pu} / \mathrm{Ac}=1 \\
\mathrm{Pu} / \mathrm{Pul}=5 \\
\mathrm{Pu} / \mathrm{Pt}=2\end{array}$ & & $\mathrm{~N}^{\circ} 02=8$ & & $\begin{array}{l}\mathrm{Np}=7 \\
\mathrm{Ad}=1\end{array}$ \\
\hline $\begin{array}{l}\text { Los Horcones } \\
(37: 615)\end{array}$ & $\begin{array}{l}M A=5 \\
A=18 \\
C=14\end{array}$ & $\mathrm{PI}=37$ & $\begin{array}{l}\mathrm{Al} / \mathrm{Ac}=1 \\
\mathrm{Pu} / \mathrm{Pul}=6 \\
\mathrm{Pu} / \mathrm{In}=2 \\
\mathrm{Pu} / \mathrm{Gr}=3 \\
\mathrm{Al} / \mathrm{Pt}=11\end{array}$ & $\mathrm{Pu} / \mathrm{Pt}=14$ & $\begin{array}{l}\mathrm{N}^{\circ} 02=28 \\
\mathrm{~N} 007=2 \\
\mathrm{~N} 009=4 \\
\mathrm{No} 8,12,13\end{array}$ & & $\begin{array}{l}\mathrm{Np}=22 \\
\mathrm{Ad}=8 \\
\mathrm{Ad} / \mathrm{Icp}=5 \\
\mathrm{Sm} / \mathrm{Icp}=1 \\
\mathrm{Ad} / \mathrm{Sm} / \mathrm{Icp}=1\end{array}$ \\
\hline $\begin{array}{l}\text { El Potrerillo } \\
(15: 615)\end{array}$ & $\begin{array}{l}\mathrm{MA}=7 \\
\mathrm{~A}=2 \\
\mathrm{C}=6\end{array}$ & $\mathrm{PI}=15$ & $\begin{array}{l}\mathrm{Pu} / \mathrm{Pul}=4 \\
\mathrm{Al} / \mathrm{In}=3 \\
\mathrm{Pu} / \mathrm{In}=2\end{array}$ & $\begin{array}{l}\mathrm{Al} / \mathrm{Pt}=1 \\
\mathrm{Pu} / \mathrm{Pt}=4 \\
\mathrm{Pu} / \mathrm{In}- \\
\mathrm{Pul}=1\end{array}$ & $\begin{array}{l}\mathrm{N}^{\circ} 02=11 \\
\mathrm{~N}^{\circ} 03=2\end{array}$ & $\mathrm{~N}^{\circ} 09=2$ & $\begin{array}{l}\mathrm{Np}=11 \\
\mathrm{Ad}=1 \\
\mathrm{Ad} / \mathrm{Icp}=3\end{array}$ \\
\hline $\begin{array}{l}\text { Laguna Salada } \\
(100: 615)\end{array}$ & $\begin{array}{l}\mathrm{MA}=32 \\
\mathrm{~A}=56 \\
\mathrm{C}=12\end{array}$ & $\mathrm{PI}=100$ & $\begin{array}{l}\mathrm{Pu} / \mathrm{Pul}=39 \\
\mathrm{Al} / \mathrm{In}=4 \\
\mathrm{Pu} / \mathrm{In}=13 \\
\mathrm{Pu} / \mathrm{Gr}=22 \\
\mathrm{Al} / \mathrm{Pt}=9 \\
\mathrm{Pu} / \mathrm{Pt}=8 \\
\mathrm{Pu} / \mathrm{In}-\mathrm{Pul}=\end{array}$ & $\begin{array}{l}\mathrm{Pu} / \mathrm{Md}- \\
\mathrm{In}=1\end{array}$ & $\begin{array}{l}\text { No02=61 } \\
N^{\circ} 03=4 \\
N^{\circ} 09=15\end{array}$ & $\begin{array}{l}\text { No13=17 } \\
\text { No1,5,17 }\end{array}$ & $\begin{array}{l}\mathrm{Np}=57 \\
\mathrm{Ad}=8 \\
\mathrm{Sm}=1 \\
\mathrm{Icp}=2 \\
\mathrm{Ad} / \mathrm{Icp}=13 \\
\mathrm{Sm} / \mathrm{Icp}=15 \\
\mathrm{Ad} / \mathrm{Sm} / \mathrm{Icp}=4\end{array}$ \\
\hline $\begin{array}{l}\text { El Zorro } \\
(20: 615)\end{array}$ & $\begin{array}{l}\mathrm{MA}=11 \\
\mathrm{~A}=4 \\
\mathrm{C}=5\end{array}$ & $\mathrm{PI}=20$ & $\begin{array}{l}\mathrm{Pu} / \mathrm{Pul}=15 \\
\mathrm{Al} / \mathrm{In}=3 \\
\mathrm{Pu} / \mathrm{In}=2\end{array}$ & & $\begin{array}{l}\mathrm{N}^{\circ} 02=18 \\
\mathrm{~N} 33,9\end{array}$ & & $\begin{array}{l}\mathrm{Np}=18 \\
\mathrm{Ad}=1 \\
\mathrm{Icp}=1\end{array}$ \\
\hline El Corral & Material & mico $\mathrm{m}$ & ragmentario & & & & \\
\hline Fiambalá 1 & No se $\mathrm{r}$ & ó mater & rámico & & & & \\
\hline
\end{tabular}

Tabla 3: Composición de la muestra cerámica en función de las variables consideradas. Table 3: Composition of the ceramic sample on the basis of the variables considered. 


\begin{tabular}{|c|c|c|c|c|}
\hline \multirow{2}{*}{$\begin{array}{l}\text { Área de emplazamiento de los sitios } \\
\text { arqueológicos }\end{array}$} & \multicolumn{3}{|c|}{$\begin{array}{c}\text { Cantidad de piezas que componen los grupos definidos } \\
\text { por análisis estadístico multivariado }\end{array}$} & \multirow[t]{2}{*}{ Total } \\
\hline & Grupo 1 & Grupo 2 & Grupo 3 & \\
\hline Valle alto (1.900 m.s.n.m.) & 105 & 87 & 122 & 314 \\
\hline $\begin{array}{l}\text { Sector de la ruta a través del conector este- } \\
\text { oeste mediando el cruce de las Sierras de Las } \\
\text { Planchadas y Narváez (1.900-2.400-2.900- } \\
4.100-3400 \text { m.s.n.m.) }\end{array}$ & 106 & 75 & 0 & 181 \\
\hline Puna transicional (4.000 m.s.n.m.) & 55 & 65 & 0 & 120 \\
\hline Total & 266 & 227 & 122 & 615 \\
\hline
\end{tabular}

Tabla 4: Composición de grupos generados por análisis estadístico multivariado aplicado a la muestra cerámica

Table 4: Composition of groups generated by multivariate statistical analysis.

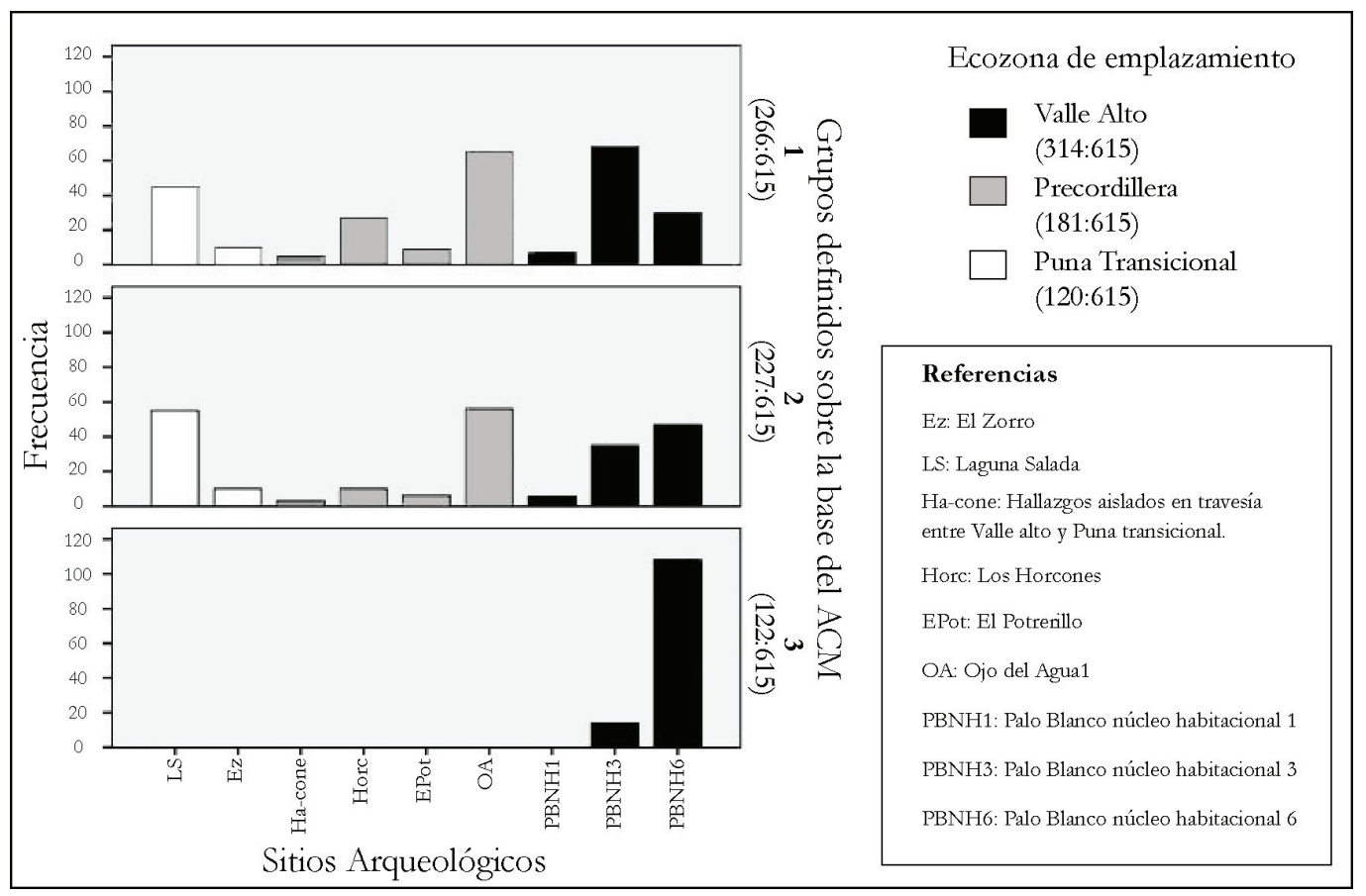

Figura 5: Frecuencia de representación de los grupos de materiales cerámicos pronosticados estadísticamente, en función de los sitios arqueológicos y sus ecozonas de emplazamiento. Figure 5: Frequency of the groups of ceramic materials predicted statistically by archaeological sites and eco-zones. 


\section{Caracteristicas arquitectónicas de los sitios}

Se observan diferencias en las materias primas y en la preparación de los materiales para la construcción de muros y cimientos según los lugares de emplazamiento de los sitios. Por un lado, en precordillera, puna y cordillera se utilizaron rocas seleccionadas por criterios de forma y tamańo, preferentemente globulares de variadas dimensiones, que provienen de las adyacencias de cada instalación (cursos fluviales o formaciones rocosas). El armado de los muros varía en cuanto a la ubicación y colocación de las rocas. En el caso de Ojo del Agua 1 (2.479 m.s.n.m.) y Fiambalá 1 (5.000 m.s.n.m.) ambos presentan muros dobles, pero mientras que la primera hilera (cimiento) está conformada por rocas de tamaño grande, de forma globular y colocadas verticalmente, para las sucesivas hileras se utilizaron rocas de forma esferoidal y de menor tamaño (Salminci 2005) (Figura 6a). Por su parte, Laguna Salada y El Zorro, en piso de 4.000 m.s.n.m., evidencian muros simples o dobles en pirca seca de rocas en forma de paralelepípedos con ángulos redondeados y otras esferoides que se colocan en forma horizontal sin diferenciación entre las hileras (Ratto et al. 2012) (Figura 6b).
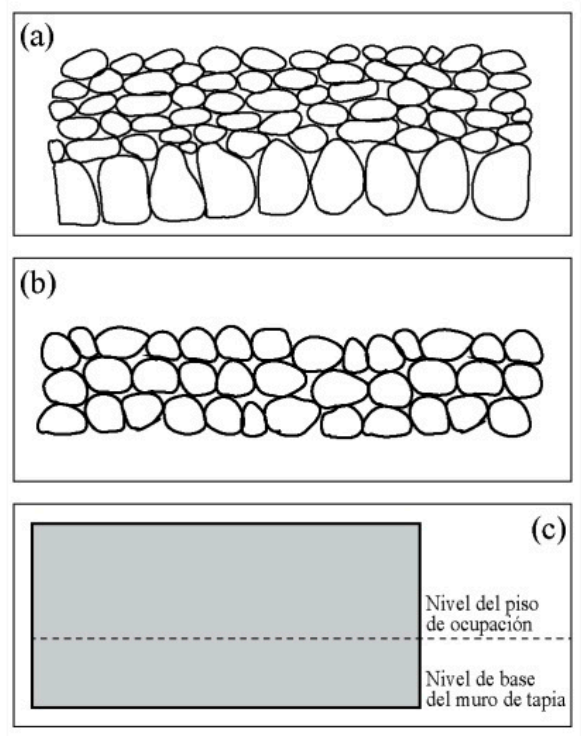

Figura 6: Esquema del armado de muros y cimientos en sitios pre-cordilleranos, de puna transicional, altoandino-cordillera y valle mesotérmico: (a) Ojo del Agua (2.479 m.s.n.m.) y Fiambalá 1 (5.000 m.s.n.m.), (b) Laguna Salada y El Zorro (4.000 m.s.n.m.), (c) Palo Blanco (1900 m.s.n.m.).

Figure 6: Outline of the building of walls and foundations in sites located on precordillera, transitional puna, high-Andean cordillera and mesothermal valley: (a) Ojo de Agua (2.479 m.a.s.l.) and Fiambalá 1 (5000 m.a.s.l.), (b) Laguna Salada and El Zorro (4000 m.a.s.l.), (c) Palo Blanco (1900 m.a.s.l.). 
Por otro lado, en el valle alto (Palo Blanco, 1.900 m.s.n.m.) se utilizaron materiales de la tierra (sedimentos arcillosos) que fueron moldeados mediante la técnica de encofrado (tapia) sin preparación de cimientos levantados con roca (Martino et al. 2006, Ratto y Basile 2010) (Figura 6c). En estos casos las bases de los muros se encuentran entre los 50 y $60 \mathrm{~cm}$ de profundidad respecto del nivel del piso de ocupación de los recintos.

\section{DisCUSIÓN Y CONCLUSIONES}

Como hemos visto, existen numerosas vías de comunicación que, tanto en dirección norte-sur como este-oeste, articulan las dimensiones físicas, sociales y simbólicas del espacio construido en el oeste tinogasteño entre los años 200 al 1.200 de la era. Aquí hemos presentado en detalle la ruta por las quebradas de los ríos Agua de la Cañada y La Cuesta que vincula el bolsón de Fiambalá con el área puneńa-cordillerana de Chaschuil y sus posibles empalmes. Diferentes sitios se emplazan dentro de este recorrido que relaciona el valle mesotérmico $(1.900$ m.s.n.m.) con la puna transicional (4.000 m.s.n.m.) y la alta cordillera andina (5.000-6.730 m.s.n.m.). Este espacio no sólo está marcado por la localización de los lugares de residencia, permanente o temporal, sino también por la construcción de apachetas en las abras o portezuelos, la presencia de manifestaciones rupestres y la evidencia de realización de prácticas rituales que, según Ratto y Orgaz (2009), tuvieron la finalidad de controlar y/o apaciguar la actividad volcánica. Resulta interesante destacar que todas las opciones de comunicación convergen en Cazadero Grande (3.400 m.s.n.m.), un paraje vinculado con la caza de camélidos a lo largo del tiempo (Ratto 2003, Ratto y Orgaz 2008).

Los nuevos indicadores explorados en la materialidad cerámica y arquitectónica apoyan la hipótesis de integración de las distintas ecozonas en momentos de las sociedades pre-tardías que habitaron la región (ca. 2001.200 ańos A.D.), reforzando de esta manera lo que veníamos sosteniendo a través de los estudios de procedencia de materias primas cerámicas (Ratto et al. 2004). Consideramos que dichos indicadores dan cuenta de las elecciones técnicas implementadas tanto en la manufactura de objetos cerámicos como en la construcción de los sitios arqueológicos, que involucran prácticas constituidas socialmente, reflejando la existencia de un entendimiento y un código compartido acerca de cómo las cosas deben hacerse en ese momento y en ese lugar.

Los objetos cerámicos recuperados en las instalaciones emplazadas en los distintos ambientes conectados presentan los mismos modos de 
preparación de pastas, formas de piezas, técnicas de resolución visual, combinaciones de unidades morfológicas y tipos de articulación utilizados en la configuración de las representaciones desplegadas en ellos. Es significativa la amplia distribución tempo-espacial de las técnicas implementadas y de la recurrencia del tránsito por los distintos ambientes del extenso conector entre los 200 y 1.200 ańos de la era, aproximadamente (Tabla 1). Por lo tanto, consideramos que los resultados obtenidos están dando cuenta de la existencia de una tradición alfarera que se reproduce en el tiempo, trasmitiéndose dentro de la región a partir de una memoria que es construida y reconstruida durante el proceso. Por su parte, la arquitectura también nos está mostrando la reproducción de técnicas constructivas a lo largo del tiempo, diferenciándose los lugares de residencia permanente de aquellos estacionales o temporarios. Sin embargo, esta diferenciación se da sólo respecto al uso de los materiales pero no en cuanto a la organización socioespacial de los lugares construidos (Ratto et al. 2008). Es interesante que el sitio pre-tardío Ranchillos 2 (Salminci 2005, Sempé 1976), emplazado a 2.390 m.s.n.m. en ambiente precordillerano y relacionado con la ruta presentada, reúna las mismas características constructivas que los sitios Ojo del Agua 1 y Fiambalá 1.

Sin embargo, vemos diferencias interesantes en estos casi 1.000 años de tránsito entre las tierras bajas y altas del oeste catamarqueño. Al respecto, determinadas elecciones técnicas aplicadas en los objetos cerámicos recuperados en el valle mesotérmico no se registran en los otros emplazamientos del conector a partir del año 750 de la era, aproximadamente. Este resultado es interesante ya que puede estar indicando, por un lado, un cambio en los aspectos tecnológicos de preparación de las pastas y, por el otro, en los patrones de movilidad de las poblaciones, ya que para esos tiempos es posible que la ruta analizada dejara de ser transitada. Esto nos permite pensar que entre los años 700-900 años de la era, la comunicación entre ecozonas a través de este conector se discontinúa. La interrupción de su uso puede estar relacionada con los cambios ambientales por actividad volcánica de alcance regional (Montero et al., 2009) que posiblemente se reflejaron en movimientos de pueblos, cambios en el uso de la tierra y/o despoblamiento del valle alto mesotérmico. Es interesante que a lo largo del relevamiento de la ruta no se hayan documentado ni sitios ni hallazgos cerámicos aislados correspondientes a momentos tardíos o pre-incaicos.

A pesar de que en el lapso entre los años 700 al 900 AD esta vía de comunicación este-oeste no se utilizó, los pisos de altura continuaron siendo ocupados tal como lo indican los fechados procedentes de algunos sitios 
emplazados en la puna transicional (ver Tabla 1 y Figura 2). Por lo tanto, es posible que se utilizaran las otras vías de comunicación mencionadas en este trabajo u otras aún no relevadas. Cabe aclarar que los fechados más tardíos de los contextos pre-tardíos provienen del sitio El Corral, cuyo material cerámico no reunió los criterios de selección para ser analizado. Sin embargo, podemos afirmar que este conjunto presenta características tecnológicas y técnicas similares a los casos que conforman los Grupos No 1 y No 2 del análisis estadístico multivariado (ver más atrás). Por lo tanto, es posible que la tradición alfarera formativa que hemos definido sobre la base de las variables morfológicas, tecnológicas y visuales analizadas, se extendiera en el tiempo desde los años 200 hasta el 1.200 de la era en el oeste catamarqueño, pero con representación diferencial en las tierras altas con respecto a las bajas. Mientras que en el valle la profundidad temporal de esta tradición alfarera llega al año 900, en las tierras altas puneñas se extiende hasta el 1.200, desafiando los modelos de periodización vigentes (Ratto et al. 2004). Por su parte, las técnicas constructivas que emplearon rocas para la construcción de los muros se mantuvieron en el tiempo, ya que en la precordillera, puna transicional y altoandino se registraron las mismas formas de armar los cimientos en sitios conectados por la ruta dentro del lapso del 400 al 1000 AD. Es interesante que esas técnicas convivieron con otra (tapia) que sólo empleó materiales de la tierra para levantar los muros pero sólo fue registrada en el valle mesotérmico dentro de ese rango temporal. Lo concreto, es la reproducción de modos similares para manufacturar y configurar visualmente los objetos cerámicos y construir los lugares que la gente incorpora y usa a lo largo de su vida, reutilizando los espacios que vinculan las tierras bajas y altas del oeste catamarqueño. El tránsito por esta ruta fue fundamental en la construcción de una memoria, un conocimiento y un código compartidos, generados en el curso mismo de la experiencia de recorrer y habitar esos lugares.

Agradecimientos: Nuestro agradecimiento a todos los que contribuyeron en los trabajos de campo en el marco de los proyectos CFI No 6123, UBACyT F063 y PICT-2007-01539 (Dir. N. Ratto). Extendemos también el agradecimiento a los evaluadores anónimos por sus valiosas observaciones y comentarios que contribuyeron a mejorar sustancialmente este trabajo. 


\section{Notas}

1 Las rutas en sentido norte-sur tienen un corredor principal que nace en La Troya ( 1.450 m.s.n.m.) y cruza las serranías de El Calvario que se convierte en punto nodal, ya que se puede continuar en dirección norte llegando hasta el pie de las estribaciones de la Cordillera de San Buenaventura o seguir con rumbo noroeste para empalmar con otras rutas de comunicación este-oeste (Zanjón de Apocango-Anchoca; por el río Abajo y por los ríos Agua de La Cańada y La Cuesta) (Ratto 2006).

2 El motivo por el cual los conjuntos cerámicos procedentes de estos sitios no se incluyen en el análisis consiste en que: (i) algunas de las manifestaciones culturales son de tiempo incaico (Orgaz 2001, Ratto 2000, 2003), mientras que (ii) en otras, adscriptas al lapso abordado en este trabajo, aún no se realizaron intervenciones sistemáticas, particularmente en sitios emplazados en ambiente altoandino de las nacientes del río Cazadero Grande. Se aclara que se tiene conocimiento de su existencia a través del registro fotográfico y de recolecciones asistemáticas realizadas por andinistas.

$3 \mathrm{Si}$ bien los sitios en Ojo de Las Lozas (4.000 m.s.n.m.) presentan arreglos arquitectónicos y conjuntos cerámicos correspondientes a tiempos formativos (Ratto et al. 2002, Ratto 2003), aún no se han realizado intervenciones sistemáticas debido a la compleja logística que se necesita hoy en día para acceder al lugar y mantener un grupo trabajando varios días. Por lo tanto, tampoco se incluye en este trabajo.

4 Cabe aclarar que estas rutas fueron utilizadas por lugareños para acceder a los territorios de caza de camélidos en las tierras altas.

\section{BibLIOGRAFÍA}

Aschero, C. 1975. "Motivos y objetos decorados del sitio precerámico Inca Cueva 7 (provincia de Jujuy)". Antiquitas 20-21: 2-7.

----- 2006. "De cazadores y pastores. El arte rupestre de la modalidad río Punilla en Antofagasta de la Sierra y la cuestión de la complejidad en la Puna Meridional argentina". En Tramas en la Piedra. Producción y usos del arte rupestre, editado por D. Fiore y M. M. Podestá, pp: 103-140. Asociación Amigos del Instituto Nacional de Antropología (AINA), World Archaeological Congress (WAC) y Sociedad Argentina de Antropología, Buenos Aires.

2012. Arte Rupestre, Contexto y Sociedad en el Desierto Puneño. Tesis para optar al título de Doctor en Arqueología, Facultad de Filosofía y Letras, Universidad de Buenos Aires. Argentina.

Balesta, B. 2000. La Significación en la Funebria de La Ciénaga. Tesis paraoptar al título de Doctor en Arqueología, Facultad de Ciencias Naturales y Museo, UNLP. La Plata, Argentina.

Basile, M. 2011. Continuidades y rupturas en las representaciones plásticas del Formativo (ca. 200 AD) a la ocupación incaica (ca. 1480 AD) en la región de Fiambalá (pcia. de Catamarca). Tesis para optar al título de Doctor en Arqueología, Facultad de Filosofía y Letras, Universidad de Buenos Aires. Argentina.

Basile, M. y Ratto, N. 2010. Imágenes sobre rocas del sudoeste tinogasteño (Catamarca, ca. 2500 y el 1300 A.P.). Arqueología 17: 13-34. 
----- 2011. “Colores y surcos. Una propuesta metodológica para el análisis de las representaciones plásticas de la región de Fiambalá (Tinogasta, Catamarca, Argentina)". Boletín del Museo Chileno de Arte Precolombino 16(2): 75-88.

Berenguer, J. 1994. "Asentamientos, caravaneros y tráfico de larga distancia en el Norte de Chile: el caso de Santa Bárbara". En De costa a selva. Producción e intercambio entre los pueblos agroalfareros de los Andes centro-sur, editado por M. E. Albeck, pp: 17-50. Instituto Interdisciplinario Tilcara, FF y L, UBA, Buenos Aires.

Bonomo, N., A. Osella y N. Ratto. 2010. "Detecting and mapping buried buildings with GPR at an ancient village in Northwestern Argentina". Journal of Archaeological Science 37: 3247-3255.

Feely, A. 2010. Estilos Tecnológicos y Tradiciones Cerámicas del Bolsón de Fiambalá (Dto. Tinogasta, Catamarca). Tesis para optar al título de Doctor en Arqueología, Facultad de Filosofía y Letras, Universidad de Buenos Aires. Argentina.

Feely, A. y N. Ratto. 2009. "Variaciones de los conjuntos cerámicos de unidades domésticas: aldeas y puestos Formativos del bolsón de Fiambalá (ca. 15001300 A.P.)". En Entrelazando ciencias. Sociedad y ambiente antes de la conquista española, compilado por N. Ratto, pp: 99-129. Eudeba, Buenos Aires.

Fiore, D. 2007. "The economic side of rock art. Concepts on the production of visual images”. Rock Art Research 24(2):149-160.

Gardin, J.C. 1978. Code pour l'analyse des Ornements. Editions du Centre National de la Recherche Scientifique, París.

González, A. R. y M.C. Sempé 1975. "Prospección arqueológica en el valle de Abaucán”. Revista del Instituto de Antropología II: 7-32.

Gordillo, I. 1999. "Problemas cronológicos del Período Medio en el Noroeste Argentino". Actas XII Congreso Nacional de Arqueología Argentina, Tomo II, pp: 362-371. La Plata, Argentina.

----- 2009. "Dominios y recursos de la imagen. Iconografía cerámica del valle de Ambato”. Estudios Atacameños 37:99-121.

Kandinsky, V. 2007 [1926]. Punto y Linea sobre el Plano. Contribución al Análisis de los Elementos Pictóricos. Terramar Ediciones, La Plata.

Kligmann, D. y N. Ratto. 2009. "Aportes de la sedimentología a la arqueología: el caso del sitio Fiambalá 1 (puna meridional catamarqueña)". Arqueometría Latinoamericana: 2 do. Congreso Argentino y Primero Latinoamericano, Tomo 1, pp: 199-208. CONEA-Constituyentes. Buenos Aires, Argentina. 
Lemonnier, P. 2002. Technological Choices. Transformation in Material Cultures since the Neolithic. Routledge, London and New York.

Martino,L.; N. Bonomo; E. Lascano; A. Osellay N. Ratto. 2006. "Geoelectrical and GPR joint prospecting at the Palo Blanco archaeological site, NW Argentina, A case History". Geophysics, 71(6):193-199.

Montero López, M.C., F. Hongn, R. Seggiaro, R. Marrett y N. Ratto. 2009. "Relación entre el volcanismo y los registros arqueológicos en el bolsón de Fiambalá (Departamento Tinogasta, Catamarca)". En Entrelazando ciencias. Sociedad y ambiente antes de la conquista española, compilado por N. Ratto, pp: 131-158. Eudeba, Buenos Aires.

Orgaz, M. 2001. Presencia Inkaica en los Andes Meridionales: Caso de estudio en la Cabecera Norte del Valle de Chaschuil (Tinogasta, Catamarca). CENEDIT, San Fernando del Valle de Catamarca.

Ratto, N. 2000. "La estructura del registro arqueológico en la cuenca superior del Valle de Chaschuil (Dpto. Tinogasta, Catamarca)”. Arqueología 10:39-78.

----- 2003. Estrategias de caza y propiedades del registro arqueológico en la Puna de Chaschuil (Dpto. Tinogasta, Catamarca, Argentina). Tesis para optar al título de Doctor en Arqueología, Facultad de Filosofía y Letras, Universidad de Buenos Aires. Argentina.

----- 2006. Paisajes y rutas prehispánicas, históricas y tradicionales que integraron el valle de Fiambalá y la puna meridional catamarqueña (Departamento Tinogasta, Catamarca). Informe Final presentado al Consejo Federal de Inversiones y Secretaría de Turismo de la Provincia de Catamarca. Manuscrito en posesión del autor.

2007. "Paisajes Arqueológicos en el Tiempo: La interrelación de ciencias sociales, físico-químicas y paleoambientales (Dpto. Tinogasta, Catamarca, Argentina)". En Producción y Circulación Prehispánicas de bienes en el Sur Andino, compilado por A. Nielsen, M. C. Rivolta, V. Seldes, M. Vázquez y P. Mercolli, Tomo 2, pp: 35-54. Editorial Brujas, Córdoba.

Ratto, N y M. Basile. 2010. "La localidad arqueológica de Palo Blanco (Dpto. Tinogasta, Catamarca): Nuevas Evidencias”. Editado por R. Bárcena y H. Chiavazza, Arqueología Argentina en el Bicentenario de la Revolución de Mayo, Tomo IV: 1707-1712, Mendoza.

Ratto, N. y M. Orgaz. 2008. "Transformaciones sociales de la Cacería Comunal de Vicuñas desde los Inkas hasta las comunidades andinas actuales". En: Zooarqueología Hoy. Encuentros Hispano-Argentinos, editado por J. Carlos Díez, pp: 109-123. Universidad de Burgos, Burgos. 
2009. "Poder, control y volcanes: El estado Inka en el volcán Incahuasi. (Tinogasta, Catamarca, Argentina)". En Entrelazando ciencias. Sociedady ambiente antes de la conquista española, compilado por N. Ratto, pp:159174. Eudeba, Buenos Aires.

Ratto, N. y M. De Nigris. 2012. "El consumo de camélidos (Lama Vicugna) en un sitio ceremonial de la alta cordillera andina (Dpto. Tinogasta, Catamarca, Argentina)". Chungara. En prensa.

Ratto, N; M. Orgaz, G. De La Fuente y R. Plá. 2002. “Ocupación de pisos de altura y contexto de producción cerámica durante el Formativo: el caso de la región puneña de Chaschuil y su relación con el Bolsón de Fiambalá (Dpto. Tinogasta, Catamarca)”. Estudios Atacameños 24:51-69.

Ratto, N; Orgaz, M. y Plá, R. 2004. "La Explotación del Alfar de La Troya en el Tiempo: Casualidad o Memoria (Departamento Tinogasta, Catamarca, Argentina”. Chungara 36 (2): 349-361.

Ratto, N; A. Feely y P. Salminci. 2008. "Diseños arquitectónicos y propiedades del registro arqueológico cerámico en el valle de Fiambalá (Departamento Tinogasta, Catamarca)". En Problemáticas de la Arqueología Contemporánea, Tomo II, pp: 771-775. Universidad Nacional de Río Cuarto, Río Cuarto.

Salminci, P. 2005. Estilo constructivo y estructura espacial. Un estudio sobre etnicidad y organización social de poblaciones prehispánicas a través del análisis de la arquitectura arqueológica del valle de Fiambalá. Tesis para optar al grado de Licenciado en Antropología, orientación arqueológica, Facultad de Filosofía y Letras, UBA. Manuscrito en posesión del autor.

Scott, R. 1962 [1951]. Fundamentos del Diseño. Editorial Lerú, Buenos Aires.

Sempé, M.C. 1976. Contribución a la arqueología del valle de Abaucán. Tesis para optar al grado de Doctor en arqueología, Facultad de Ciencias Naturales y Museo, Universidad Nacional de La Plata, Buenos Aires. Ms.

1977. Caracterización de la cultura Saujil. Obra del Centenario del Museo de La Plata. Antropología II: 211-235. 